2021-05

Fatigue crack growth of natural

rubber/butadiene rubber blend

containing waste tyre rubber powders

Abang Ismawi Hassim, DH

http://hdl.handle.net/10026.1/16771

10.4028/www.scientific.net/SSP.317.293

Solid State Phenomena

Trans Tech Publications

All content in PEARL is protected by copyright law. Author manuscripts are made available in accordance with publisher policies. Please cite only the published version using the details provided on the item record or document. In the absence of an open licence (e.g. Creative Commons), permissions for further reuse of content should be sought from the publisher or author. 


\title{
Fatigue Crack Growth of Natural Rubber/Butadiene Rubber Blend Containing Waste Tyre Rubber Powders
}

\author{
Dayang Habibah Abang Ismawi Hassim ${ }^{1, a *}$, Frank Abraham², b, \\ John Summerscales ${ }^{3, c}$, Paul Brown ${ }^{4}$, \\ ${ }^{1}$ Malaysian Rubber Board, RRIM Experiment Station, 47000, Sg.Buloh, Selangor, Malaysia \\ ${ }^{2,3}$ School of Engineering, University of Plymouth, Plymouth PL4 8AA, United Kingdom \\ ${ }^{4}$ Tun Abdul Razak Research Centre (TARRC), Malaysian Rubber Board, Brickendonbury, SG13 8 \\ NL Hertford, United Kingdom \\ a*dyghabibah@gmail.com, bfrank.abraham@plymouth.ac.uk, cJ.Summerscales@plymouth.ac.uk, \\ dpbrown@tarrc.co.uk
}

Keywords: Fatigue crack growth, Recycled rubber powder, Natural rubber/butadiene rubber blend, Hysteresis

\begin{abstract}
Fatigue crack growth in NR/BR compound and the effect of two different types of recycled rubber powder (RRP) i.e. micronized cryo-ground $74 \mu \mathrm{m}$ and ambient-ground $400 \mu \mathrm{m}$ were studied using fracture mechanics approach. Absolute and relative hysteresis losses using single-edge notch tensile (SENT) specimens were determined with a displacement-controlled strain compensating for permanent set of the samples throughout the Fatigue Crack Growth (FCG) experiments. Results indicated a correlation between absolute/relative hysteresis loss and fatigue crack growth rate under specific dynamic strain amplitudes. Differences in relative hysteresis loss showed that additional energy dissipation, due to multiple new crack surfaces at the crack tip, contributes to the FCG of the RRP compounds. At higher tearing energy, beside other factors affecting the FCG performance of the RRP compounds, both higher absolute and relative hysteresis loss are slightly detrimental to the crack growth rates.
\end{abstract}

\section{Introduction}

Mechanical properties such as tensile strength, abrasion and tear resistance give simple and quick information which are often used for quality control of rubber compounds. However, these tests do not describe rubber performance in dynamic conditions. Wear loss in tyres or cracking in rubber mountings is usually associated with crack growth due to repeated cyclic stress. Therefore, crack growth resistance is of great importance in determining the strength and durability of rubber products. Intensive research [1-7] has been conducted on the basic mechanical properties of materials containing recycled rubber powder (RRP) or surface treated RRP and on the optimisation of their incorporation, but very limited research was conducted into the fatigue behaviour of the materials. In dynamic applications, it is essential to understand the fatigue behaviour of such materials to predict the fatigue lives of these rubber products which are usually exposed to extended periods of cyclic loading, and thereby ensure the necessary service life.

Han et al. [8] studied the crack growth and fatigue life of NR and SBR filled vulcanisates with the addition of various sizes of RRP and different concentrations. They reported that crack growth was reduced with increased concentration and decreasing particle size of the ground rubber powders. Similar results were obtained for fatigue life and the effect was more prominent for SBR vulcanisates compared to NR. Comparing the fatigue growth rate, NR vulcanisates possess a lower crack growth rate than SBR due to its Stress-induced crystallisation (SIC) properties [9]. In the case of filled vulcanisates containing RRP, Han et al. [8] observed that the crack growth rate of SBR and NR were quite similar and assumed that the SIC of NR probably did not occur. They stated that the presence of ground rubber particle in situ at the crack tip might suppress the SIC effect. The authors [8] used DeMattia flex cracking (DMFC) for crack growth rate measurement. Findings by other researchers 
[10-12] highlighted the contradictory performance of rubber compounds at different tearing energies. This suggests that the energetic approach for crack growth analysis would be appropriate for the RRP evaluation which is focus for this paper. In the present work, fatigue crack growth in NR/BR blend (70/30 compound) with cryogenic-ground Micronised Rubber Powder (at < $74 \mu \mathrm{m}$ denoted MRP074) was compared to ambient-ground Crumb Rubber Powder (at $<400 \mu \mathrm{m}$ denoted CRP400) using a fracture mechanics approach.

\section{Experimental}

Materials. The rubber matrix was NR/BR blend system (70/30 ratio). The blend ratio of 70/30 was selected [13] to balance properties such as abrasion, strength, fatigue and crack growth resistance for tyre tread formulation. Driven by their target properties, other authors have used NR/BR ratios of $50 / 50$ [14, 15] or 60/40 [16]. The NR was Standard Malaysian Rubber (SMR) 10. BR was cis-1,4 polybutadiene rubber (Europrene Neo cis-BR-40). The CRP400 and MRP074 recycled materials were from different batches of truck tyres. Crumb rubber powder (CRP400) at 40 mesh $(\sim 400 \mu \mathrm{m})$ particle size, was supplied by Crumb Rubber Ltd. (Plymouth, UK). Micronised Rubber Powder (MRP-Polydyne ${ }^{\mathrm{TM}} 200$ ), at 200 mesh $(74 \mu \mathrm{m})$, was supplied by Lehigh Technologies (Georgia, USA). The waste tyre rubber powder characterisation of those materials is published elsewhere [17]. For each type, the waste tyre concentration was added as $10 \mathrm{pphr}$ to the formulation. Other chemical ingredients used were zinc oxide (3.5 pphr), stearic acid (2.5 pphr), Antilux 654 wax (1 pphr), N-1,3dimethylbutyl-N' phenyl-p-phenylenediamine (6PPD, 2.5 pphr), 2,2,4-trimethyl-1,2dihydroquinoline (Flectol TMQ antioxidant, 1 pphr) N234, carbon black (30 pphr), and all of commercial grade. The curatives, $1.2 \mathrm{pphr}$ sulphur and $1 \mathrm{pphr}$ TBBS (N-tert-butyl-2-benzothiazole sulphenamide), were added during final mixing. All rubber and chemical ingredients were supplied by Tun Abdul Razak Research Centre (TARRC), Brickendonbury, UK.

Mixing process and compound preparation. NR was masticated to reduce the viscosity to a nominal 60 Mooney units (ML(1+4) at $\left.100^{\circ} \mathrm{C}\right)$, using a Bridge cracker mill, (406 mm Ø x $508 \mathrm{~mm}$ length) then a two-roll mill (Francis Shaw-50kg capacity). Three master batches of NR/BR compound were prepared using a Polylab 2000E internal mixer $\left(390 \mathrm{~cm}^{3}\right.$ and fill factor of 0.72$)$. The raw NR and BR were mixed simultaneously before addition of carbon black, RRP and other compounding ingredients. The masterbatch mixing was carried out with a starting temperature of $40^{\circ} \mathrm{C}$ and a rotor speed of $60 \mathrm{rpm}$. Total mixing time was about $6.5 \mathrm{~min}$. The masterbatches were allowed to cool overnight before the curatives were added separately using a two-roll mill. Each mix was then sheeted out at approximately $4-5 \mathrm{~mm}$ thickness.

The optimum curing times, $t_{95}$ (time at $95 \%$ of the maximum torque rise) of all samples were obtained at $160^{\circ} \mathrm{C}$ for $30 \mathrm{~min}$, using a Monsanto MDR 2000 rheometer with $0.5^{\circ}$ arc in accordance with the BS ISO 6502:2016 standard. The $229 \mathrm{~mm}$ square by $2 \mathrm{~mm}$ thick sheets were compression moulded at $160^{\circ} \mathrm{C}$ with $8 \mathrm{MPa}$ pressure using their respective optimum cure times.

Fatigue crack growth (FCG) test. FCG tests were conducted on an Instron Electropuls 3000 with a $250 \mathrm{~N}$ load cell, at ambient conditions, using displacement control mode with a superimposed minimum load control. FCG tests were carried out on NR/BR carbon black filled compound (control) with 10 pphr of either MRP074 or CRP400 filler. Single-edge notched tensile (SENT) dumbbell shape specimens had a rectangular cross-section of $15 \times 2 \mathrm{~mm}$ with $40 \mathrm{~mm}$ distance between grips from the total specimen length of $100 \mathrm{~mm}$. An initial crack of approximately $0.65 \pm 0.15 \mathrm{~mm}$ was cut into the narrow edge of each rubber specimen using a sharp razor blade. The specimens were quasi-statically stretched to $18 \mathrm{~mm}(\sim 107 \%$ strain) maximum displacement to introduce a natural crack shape prior to dynamic testing. Three specimens per amplitude were then individually subjected to a sinusoidal excitation at a frequency of $5 \mathrm{~Hz}$ with $6,9,11$ and $15 \mathrm{~mm}$ strain amplitude which corresponds respectively to $40 \%, 59 \%, 71 \%$ or $96 \%$ dynamic strain. The targeted minimum load was fixed to $1 \mathrm{~N}$ ( $\sim 0.04 \mathrm{MPa})$ with constant peak displacement using tri-modal control of the Instron WaveMatrix ${ }^{\mathrm{TM}}$ test software. The tests were periodically stopped at a specific number of cycles and the image of the 
crack was captured by a camera (computar®, MLH-10X) with optimal illumination. The posttreatment measurement of the crack length was conducted using ImageJ [18] software with semiautomatic ABSnake plugins [19]. The half crack contour lengths were measured at a specific number of cycles. The crack growth rate $(\mathrm{dc} / \mathrm{dn})$ from the stable crack growth region was obtained within the linear slope of the crack length $(c)$ plotted against the number of elapsed fatigue cycles. The cyclic crack growth rate measurement was elaborated elsewhere by Hassim et al.[20]

Hysteresis loss. Measurement of the hysteresis loss from the energy densities (total and strain energy) was acquired using the same SENT specimen during the FCG test. The hysteresis loss/energy dissipated is defined as the difference between total work done for cyclic loading, $\left(\mathrm{U}_{\mathrm{a}}\right)$ and cyclic unloading/retraction, $\left(\mathrm{U}_{\mathrm{s}}\right)$ obtained from integral area under the cyclic force displacement curve. Total energy density, $\mathrm{W}_{\mathrm{a}}$, and strain energy density, $\mathrm{W}_{\mathrm{s}}$, were determined by dividing the $\mathrm{U}_{\mathrm{a}}$ and $\mathrm{U}_{\mathrm{s}}$ by the volume of the specimen between specimen grips during cyclic loading. As the test was conducted under non-relaxing conditions (minimum load $>0$ ), the energy at the minimum strain level $\left(\mathrm{U}_{\min }\right)$ is included in both the total and strain energy. All the energy measurements were obtained from a representative stress-strain hysteresis loop at the number of fatigue cycles closest to $50 \%$ of the service life for each specimen. Percentage of relative hysteresis $\left.\mathrm{H}_{\mathrm{r}}[\%]=\left(\mathrm{W}_{\mathrm{a}}-\mathrm{W}_{\mathrm{s}}\right) / \mathrm{W}_{\mathrm{a}}\right) \times 100$ and absolute hysteresis density $\mathrm{H}_{\mathrm{ab}}=\left(\mathrm{W}_{\mathrm{a}}-\mathrm{W}_{\mathrm{s}}\right)$ were then determined.

\section{Results and discussion}

FCG of NR/BR compound and effect of CRP400 or MRP074 filler. The effect of MRP074 or CRP400 at 10 pphr loadings on FCG characteristics of NR/BR blend compound is shown in Fig. 1. At the lower tearing energy (40\% dynamic strain), the crack growth rate of CRP400 filled (10pphr) NR/BR compound was slightly lower, but not significantly different, from the control compound due to the relatively high scatter in the results. However, both CRP400 and NR/BR compounds exhibited lower crack growth than MRP074 filled compound. Both dynamic strain energy density [21, 22] and hysteresis loss [23] parameters could be used to evaluate the crack growth resistance of rubber compounds. Table 1 shows that at $40 \%$ or $59 \%$ dynamic strain amplitudes, CRP400 compound exhibits lower strain energy densities compared to the control and MRP074 filled compound within the experimental error. The lower strain energy density corresponds to a reduced energy available for crack propagation which would partially explain the lower crack growth of CRP400 filled NR/BR compound at 40 or $59 \%$ dynamic strain.

The correlation between the absolute hysteresis with the average crack growth rate or tearing energy for NR/BR or RRP filled NR/BR compounds using SENT specimen is shown in Fig. 2. The crack growth rate or tearing energy of the compounds increases with increasing absolute hysteresis loss. The addition of filler has been shown to increase hysteresis [24] in the rubber matrix, with the extent depending upon the type and amount of filler. Higher hysteresis could reduce the energy available for crack propagation [25] and is important for rubber reinforcement. Thus, the increase in absolute hysteresis loss due to introduction of RRP is expected when part of the strain energy density is dissipated as heat while the other parts act as crack/fracture driving force [26]. The non-linear correlation between the properties indicates that factor such as SIC plays an important role at specific dynamic strain amplitudes and could partially delay the crack growth rates of the rubber compounds.

Fig. 3 shows correlation between crack growth rates or tearing energy of NR/BR control and RRP filled NR/BR compound vs relative hysteresis loss at 59\%, 71\% and $96 \%$ strain amplitude with excluded data points at $40 \%$ dynamic strain. According to Neogi et al. [27] that mechanism of hysteresis loss at low strain and high strain is different, therefore there is no clear correlation of the relative hysteresis loss if all strains tested was included. From the figures (Fig. 3), higher relative hysteresis loss reduced the crack growth rate and tearing energy. This indicates that fracture resistance of rubber is not only dependent on the strain energy density (crack driving force) but also on the energy dissipated around the crack tip [23]. 
The contribution of the relative hysteresis loss for all compounds is not yet fully understood but could be attributed to the multiple dissipative processes occurring at the crack tip [25]. Additional dissipation may be attributed to the SIC effect [28]. SIC increases with increasing strain amplitude and causes increased anisotropy of the material strength [29]. At higher dynamic strain during cyclic loading, strain induced crystallisation of NR will create an area at the crack tip which will prevent the crack growth in that direction. Higher SIC at the crack tip enhances crack tip blunting and branching [30].

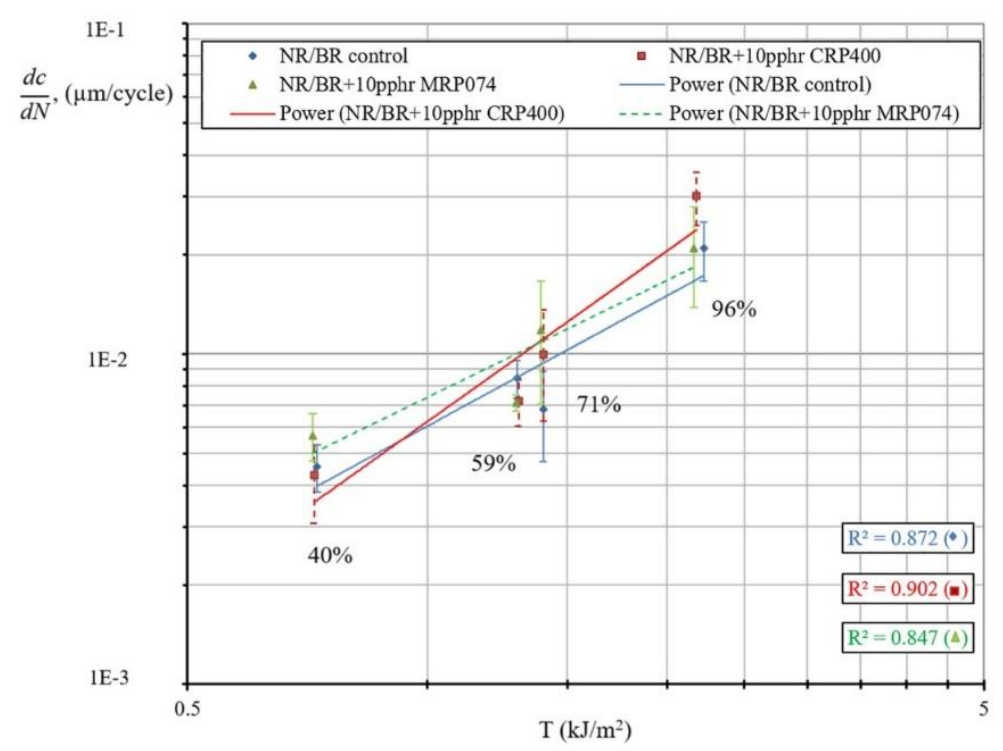

Fig. 1. Fatigue crack growth comparison with control NR/BR compound and different RRP at 10 pphr

Table 1. Total and strain energy density of NR/BR blend compound (control and CRP400 or MRP074 filled compound) at each level of dynamic strains tested

\begin{tabular}{cccc}
\hline Dynamic Strain & NR/BR & NR/BR-CRP400 & NR/BR-MRP074 \\
\hline$(\%)$ & \multicolumn{3}{c}{ Total energy density, $\mathrm{W}_{\mathrm{a}}\left(\mathrm{N} / \mathrm{mm}^{2}\right)$} \\
\hline 40 & $0.142 \pm 0.003$ & $0.137 \pm 0.001$ & $0.141 \pm 0.001$ \\
59 & $0.265 \pm 0.002$ & $0.257 \pm 0.002$ & $0.246 \pm 0.022$ \\
71 & $0.348 \pm 0.002$ & $0.341 \pm 0.005$ & $0.345 \pm 0.006$ \\
96 & $0.542 \pm 0.009$ & $0.534 \pm 0.010$ & $0.535 \pm 0.005$ \\
\hline \multicolumn{4}{c}{ Strain energy density, $\mathrm{W}_{\mathrm{s}}\left(\mathrm{N} / \mathrm{mm}^{2}\right)$} \\
\hline 40 & $0.123 \pm 0.002$ & $0.118 \pm 0.0002$ & $0.121 \pm 0.0011$ \\
79 & $0.225 \pm 0.001$ & $0.218 \pm 0.001$ & $0.232 \pm 0.024$ \\
96 & $0.298 \pm 0.002$ & $0.292 \pm 0.005$ & $0.295 \pm 0.005$ \\
\hline
\end{tabular}

The irregular (convoluted) surface of CRP400 as reported in an earlier study [17] compared to MRP074 compound provides greater surface area and a stronger interface between the particles and the rubber matrix. A stronger interface interaction/bonding was defined as the interaction level between the rubber and filler that could restrict the mobility of the rubber molecules on the filler surfaces. Thus, more contact with CB and hysteresis within the CRP400 fillers creates more internal friction contributing to higher relative hysteresis. Microscopic and macroscopic fracture surfaces after FCP test corresponding to the crack path deviation have also been reported [20]. Combined effects of additional hysteresis for CRP400 compound as a result of new surface energy could reduce the crack growth rate. 
At higher tearing energy levels (96\% dynamic strain), the crack growth rates changed to be ranked CRP400>MRP074>control NR/BR compound. There could be a competition between SIC and the crack growth. Higher crack growth rate reduces both the threshold tearing energy and the ability to crystallise [31] at the crack tip. Comparing individual relative hysteresis loss, CRP400 exhibited higher relative hysteresis loss compared to MRP074 or control filled NR/BR. Higher hysteresis dissipates heat and could increase the neighbouring network temperature which can accelerate molecular chain rupture and suppress the SIC effect at the crack tip [32].

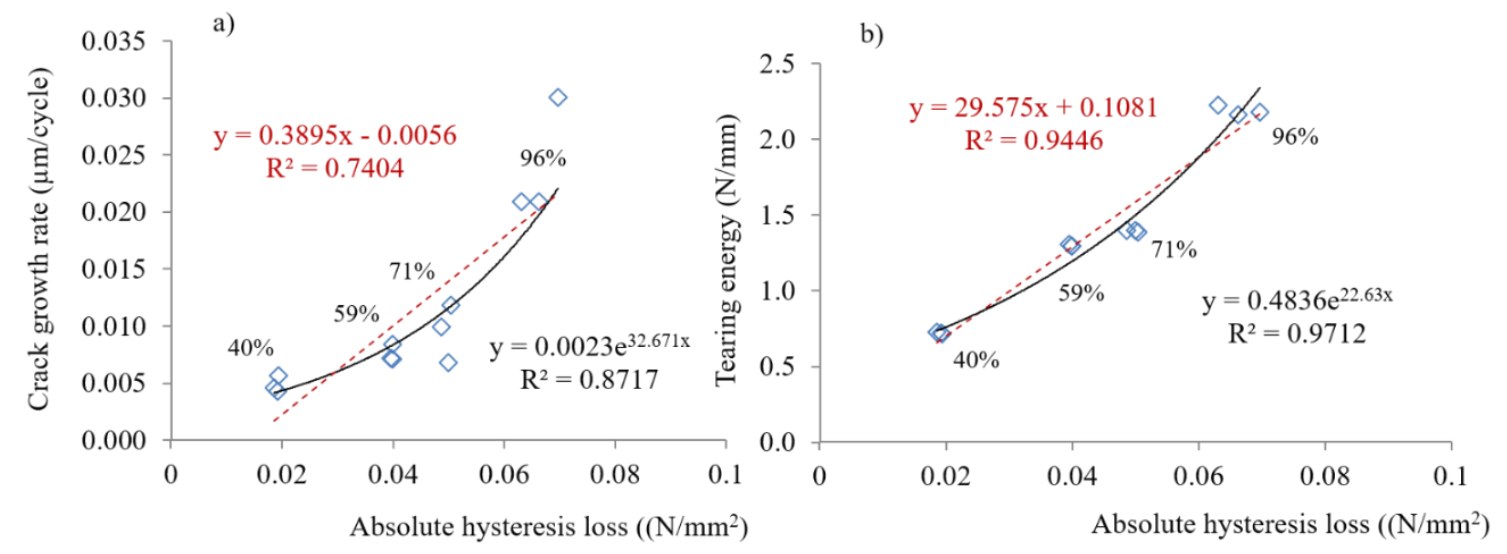

Fig 2. Correlation between crack growth rate or tearing energy of NR/BR control and RRP filled $\mathrm{NR} / \mathrm{BR}$ compound vs absolute hysteresis loss at 40\%, 59\%, 71\% and 96\% strain amplitude
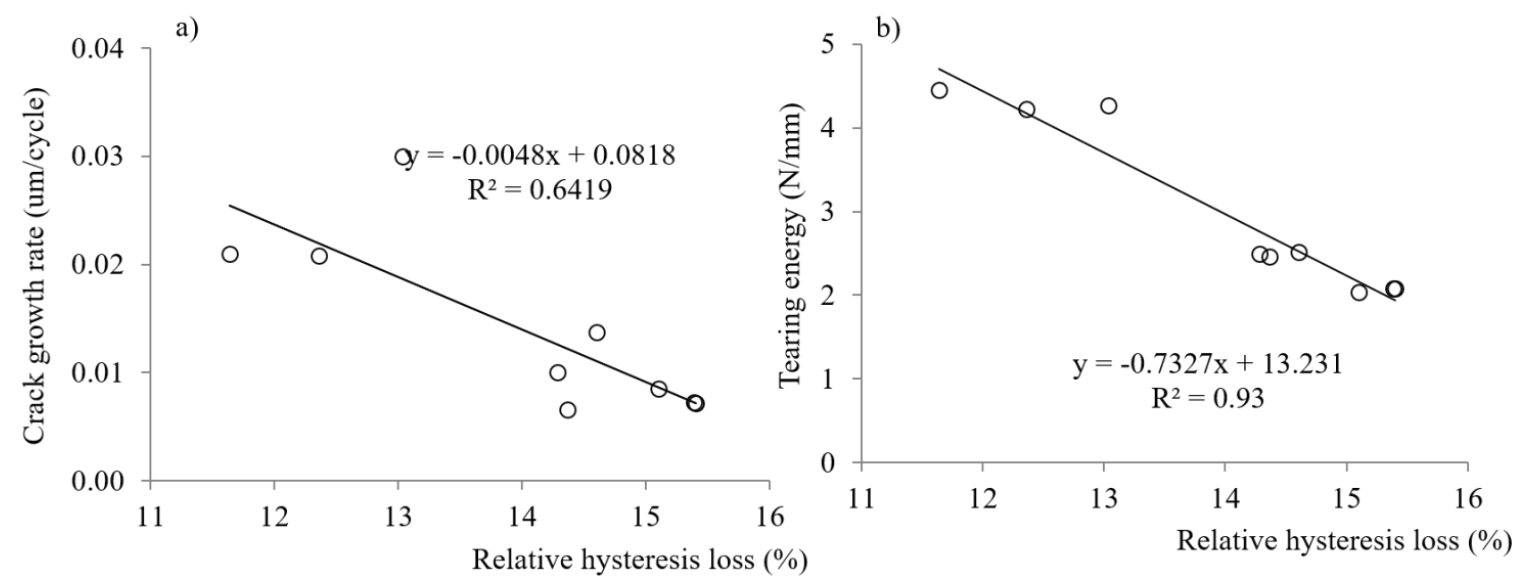

Fig. 3. Correlation between crack growth rate or tearing energy of NR/BR control and RRP filled NR/BR compound vs relative hysteresis loss at 59\%, 71\% and 96\% strain amplitude. (Data points at $40 \%$ dynamic strain excluded) 


\section{Summary}

Overall, although the average CRP400 particle diameter is about a factor five larger in one dimension than MRP074, the CRP400 compound exhibits slightly lower crack growth rate in the technically important low strains/tearing energy region. The "rougher"/irregular surface of CRP400 appears to be a more important factor than the particle size of MRP074 for the FCG performance especially at lower strains. The performance of MRP074 filled compound possibly could be improved by using optimal carbon black loading and adjusting the curing systems and will be considered for future study. Absolute and relative hysteresis loss plays an important role for the fatigue crack growth rate and tearing energy of the compounds. At higher strain (96\%), higher absolute and relative hysteresis is slightly detrimental to the fatigue crack growth rate of CRP400 compared to MRP074 filled compound.

\section{Acknowledgement}

This research has been funded by the Malaysian Rubber Board (MRB). The authors gratefully acknowledge Kenneth Halls and Paul Gladwin (Tun Abdul Razak Research Centre, TARRC), Terry Richards (School of Engineering, University of Plymouth) for their technical assistance during experimental work of this research.

\section{References}

[1] O. Grigoryeva, A. Fainleib, O. Starostenko, I. Danilenko, N. Kozak, G. Dudarenko, Ground tire rubber (GTR) reclamation: Virgin rubber/reclaimed GTR (RE) vulcanizates. Rubber Chem Technol. 77 (2004) 131-146.

[2] A.A. Yehia, M.A. Mull, M.N. Ismail, Y.A. Hefny, E.M. Abdel-Bary, Effect of chemically modified waste rubber powder as a filler in natural rubber vulcanizates. J Appl Polym Sci. 93 (2004) 30-36.

[3] T.D. Sreeja, S.K.N. Kutty, Cure characteristics and mechanical properties of natural rubber/reclaimed rubber blends. Polym Plast Technol Eng. 39 (2000) 501-512.

[4] J.K. Kim, R.P. Burford, Study on powder utilization of waste tires as a filler in rubber compounding. Rubber Chem Technol. 71 (1998) 1028-1041.

[5] N. Rattanasom, A. Poonsuk, T. Makmoon, Effect of curing system on the mechanical properties and heat aging resistance of natural rubber/tire tread reclaimed rubber blends. Polym Test. 24 (2005) 728-732.

[6] D. De, D. De, Processing and material characteristics of a reclaimed ground rubber tire reinforced styrene butadiene rubber. Materials Sciences and Applications. 2 (2011) 486-496.

[7] S. Ramarad, M. Khalid, C.T. Ratnam, A.L. Chuah, W. Rashmi, Waste tire rubber in polymer blends: A review on the evolution, properties and future. Prog Mater Sci. 72 (2015) 100-140.

[8] S.-C. Han, M.-H. Han, Fracture behavior of NR and SBR vulcanizates filled with ground rubber having uniform particle size. J Appl Polym Sci. 85 (2002) 2491-2500.

[9] G.J. Lake, P.B. Lindley, Cut growth and fatigue of rubbers. II. Experiments on a noncrystallizing rubber. J Appl Polym Sci. 8 (1964) 707-721.

[10] J.R. Halladay, F.J. Krakowski, The use of fatigue crack propagation testing in rubber compound development. Rubber World. 239 (2009) 28-31.

[11] M.D. Ellul, Mechanical fatigue, in: A.N. Gent (Ed.), Engineering with Rubber, How to Design Rubber Components. Hanser, New York, 1992, pp. 139-176.

[12] P. Ghosh, R. Stocek, M. Gehde, R. Mukhopadhyay, R. Krishnakumar, Investigation of fatigue crack growth characteristics of NR/BR blend based tyre tread compounds. International Journal of Fracture. 188 (2014) 9-21. 
[13] M.H. Halim, Truck tyre tread rubber: compounding and abrasion resistance, Loughborough University (1990)

[14] H.J. Kim, G.R. Hamed, On the reason that passenger tire sidewalls are based on blends of natural rubber and cis-polybutadiene. Rubber Chem Technol. 73 (2000) 743-752.

[15] P. Ghosh, R. Mukhopadhyay, R. Kankroli, R. Stoček, Durability prediction of NR/BR and NR/SBR blend tread compounds using Tear Fatigue Analyser. Kautsch Gummi Kunstst,2016).

[16] K. Reincke, W. Grellmann, G. Heinrich, Investigation of mechanical and fracture mechanical properties of elastomers filled with precipitated silica and nanofillers based upon layered silicates. Rubber Chem Technol. 77 (2004) 662-677.

[17] D.H. Abang Ismawi Hassim, F. Abraham, J. Summerscales, P. Brown, The effect of interface morphology in waste tyre rubber powder filled elastomeric matrices on the tear and abrasion resistance Express Polymer Letters. 13 (2019) 248-260.

[18] Information on https://imagej.nih.gov/ij/.

[19] Information on

http://imagejdocu.tudor.lu/doku.php?id=plugin:segmentation:active_contour:start.

[20] D.H. Abang Ismawi Hassim, F. Abraham, J. Summerscales, Fatigue crack growth and fatigue fracture morphology of recycled rubber powder filled NR/BR blend compound: Rubber Chemistry and Technology In-Press (2020)

[21] F. Abraham, The influence of minimum stress on the fatigue life of non strain crystallising elastomers, Coventry University (2002)

[22] B. Dong, C. Liu, Y.-P. Wu, Fracture and fatigue of silica/carbon black/natural rubber composites. Polym Test. 38 (2014) 40-45.

[23] B.N.J. Persson, O. Albohr, G. Heinrich, H. Ueba, Crack propagation in rubber-like materials. J Phys: Condens Matter. 17 (2005) R1071.

[24] A.R. Payne, Hysteresis in rubber vulcanizates. Journal of Polymer Science:Polymer Symposia. 48 (1974) 169-196.

[25] W.V. Mars, A. Fatemi, Factors that affect the fatigue life of rubber: A literature survey. Rubber Chem Technol. 77 (2004) 391-412.

[26] G. Weng, H. Yao, A. Chang, K. Fu, Y. Liu, Z. Chen, Crack growth mechanism of natural rubber under fatigue loading studied by a real-time crack tip morphology monitoring method. RSC Advances. 4 (2014) 43942-43950.

[27] C. Neogi, A.K. Bhowmick, S.P. Basu, Hysteresis Loss of Swollen Rubber Vulcanizates in Force-Retraction Measurement and Dynamic Mechanical Analysis. Journal of Elastomers \& Plastics. 23 (1991) 152-163.

[28] P.B. Lindley, Relation between hysteresis and the dynamic crack growth resistance of natural rubber. International Journal of Fracture. 9 (1973) 449-462.

[29] M. Flamm, J. Spreckels, T. Steinweger, U. Weltin, Effects of very high loads on fatigue life of NR elastomer materials. Int J Fatigue. 33 (2011) 1189-1198.

[30] G.R. Hamed, Molecular aspects of the fatigue and fracture of rubber. Rubber Chem Technol. 67 (1994) 529-536.

[31] G.J. Lake, Fatigue and fracture of elastomers. Rubber Chem Technol. 68 (1995) 435-460.

[32] B. Dong, C. Liu, Y. Lu, Y. Wu, Synergistic effects of carbon nanotubes and carbon black on the fracture and fatigue resistance of natural rubber composites. J Appl Polym Sci. 132 (2015). 